\title{
Vigorous physical activity patterns affect bone growth during early puberty in boys
}

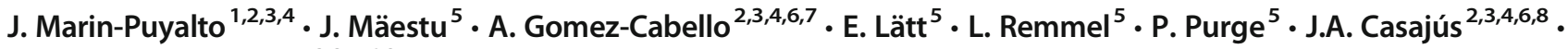 \\ G. Vicente-Rodríguez ${ }^{1,2,3,4,6,8}$ (I) $\cdot$ J. Jürimäe ${ }^{5}$
}

Received: 9 May 2018 / Accepted: 3 October 2018

(C) International Osteoporosis Foundation and National Osteoporosis Foundation 2018

\begin{abstract}
Summary This study aims to analyze the impact of participation in vigorous physical activity as it can promote a healthy bone development. Adolescents who increased their participation in vigorous physical activity showed higher improvements in bone parameters compared to those who did not, which highlights the relevance of vigorous physical activity engagement.

Introduction The main purpose of the study was to analyze the effects of different patterns of vigorous physical activity (VPA) on bone development.

Methods One-week accelerometry registers and dual-energy X-ray absorptiometry scans at the whole body, hip, and lumbar spine of 140 healthy male adolescents (11-13 years, at baseline) were performed twice with a 1-year interval between measurements. Four patterns of VPA evolution ("low-low," "low-high," "high-low," and "high-high") and three patterns of bone growth ("optimal," "mean," and "reduced") were defined according to the median participation in VPA and a cluster analysis of the longitudinal changes in BMC and BMD in all sites measured, respectively. Bone mineral parameters were adjusted for skeletal age and body weight prior to statistical comparison among groups.

Results Participants in the "low-high" group had greater adjusted BMD increases at both the femoral neck and lumbar spine when compared to the "low-low" group (estimated mean (95\% CI) $0.066(0.047-0.085)$ vs. $0.034(0.021-0.047) \mathrm{g} / \mathrm{cm}^{2}$ and $0.074(0.054-0.093)$ vs. $0.049(0.035-0.062) \mathrm{g} / \mathrm{cm}^{2}$ respectively, both $\left.p<0.05\right)$. Femoral neck BMD adjusted increase was also different between the "high-high" and the "high-low" groups $\left(0.053(0.041-0.066)\right.$ vs. $\left.0.030(0.011-0.049) \mathrm{g} / \mathrm{cm}^{2}, p<0.05\right)$. Additionally, a higher percentage of "optimal" growth was found in the "low-high" group than in the "low-low" and "high-low" categories $(36.3,12.5$ and $13.6 \%$ respectively, $p<0.05)$.

Conclusions Engaging in VPA as well as maintaining high levels of VPA during puberty is associated with greater gains in bone mass, which can have an impact in future bone health.
\end{abstract}

Keywords Accelerometry $\cdot$ Adolescence $\cdot$ Cluster analysis $\cdot$ Growth profile

Electronic supplementary material The online version of this article (https://doi.org/10.1007/s00198-018-4731-2) contains supplementary material, which is available to authorized users.

G. Vicente-Rodríguez

gervicen@unizar.es

1 Faculty of Health and Sport Science (FCSD), Department of Physiatry and Nursing, Universidad de Zaragoza, Ronda Misericordia 5, 22001 Huesca, Spain

2 GENUD (Growth, Exercise, Nutrition and Development) Research Group, Zaragoza, Spain

3 Instituto Agroalimentario de Aragón (IA2), Zaragoza, Spain

4 EXERNET red de investigación en ejercicio físico y salud para poblaciones especiales, Zaragoza, Spain
5 Institute of Sport Pedagogy and Coaching Sciences, Centre of Behavioral, Social and Health Sciences, University of Tartu, Tartu, Estonia

6 Centro de Investigación Biomédica en Red de Fisiopatología de la Obesidad y Nutrición (CIBEROBN), Madrid, Spain

7 Centro Universitario de la Defensa, Zaragoza, Spain

$8 \quad$ Faculty of Health Sciences (FCS), Department of Physiatry and Nursing, Universidad de Zaragoza, C/Domingo Miral s/n, 50009 Zaragoza, Spain 


\section{Introduction}

Osteoporosis is one of the most prevalent metabolic skeletal diseases, affecting an estimate of 27.5 million people in the European Union [1] and 10.2 million older adults in the USA [2]. The osteoporotic patients suffer a decrease in bone mineral density (BMD) that implies a reduced tolerance to stress, and consequently, even a low-magnitude impact could cause a bone fracture [3]. These fractures can result in reduced functionality, disability, and even death [4]. The management and prevention of osteoporosis is one of the main challenges for healthcare systems in developed countries [5].

Even though approximately $60-80 \%$ of bone mass is determined by genes or other unmodifiable factors $[6,7]$, lifestyle choices play a crucial role in bone mass accrual and the optimization of its influence is vital for bone health [8]. Maximizing the peak BMD attained in early adulthood [9] is an important strategy aiming osteoporosis prevention, as it is estimated that an increase of one standard deviation in peak bone mass could reduce later fracture risk up to 50\% [10].

In a systematic review, the National Osteoporosis Foundation identified and graded the evidence of the effect of various lifestyle factors on peak bone mass and strength [11]. Participation in physical activity (PA) and exercise showed the highest level of evidence for increasing peak bone mass and density [11]. Additionally, there are several reviews that indicate that participation in unstructured weight-bearing PA and sports during childhood and adolescence has strong and consistent positive effects on bone development [12-14]. It has been observed that mechanical stress stimulates an osteogenic response which can be the result of both muscle contraction and gravitational impact forces [15] both present in weight-bearing PA. This mechanical stress is required to have certain characteristics, and in order to maximize its effects on bone, it should be dynamic, intense, brief, and intermittent and including unusual loading [16], suggesting that physical activity should be vigorous and varied.

Early puberty represents an optimal window of opportunity in order to increase bone mass and strength that might not be present later in life [14]. Moreover, it has been stated that PA participation undertaken during puberty may have greater positive effects than pharmacological interventions in adults with osteoporosis [14]. It is important to highlight that PA practice during puberty may have long-term positive effects, since benefits in bone mass and structure obtained during this stage are retained later in life [17-19].

In a recent review from Poitras et al. [12], 12 crosssectional and eight longitudinal studies regarding the influence of PA on bone health during growth were described and analyzed. In an evaluation of more than 300 children in a 10-year longitudinal study, it was observed that vigourous PA (VPA) correlated with bone mineral content (BMC) at weight-bearing sites throughout all the evaluations and therefore, it was concluded that the main focus should be put in VPA interventions [20]. Regarding the necessary amount of physical activity to achieve an osteogenic response, it has been indicated that $3 \mathrm{~h}$ per week are enough to elicit an increase in bone mass [8], whereas 32 min per day of VPA participation have shown benefits for the femoral neck BMD [21].

Only one of the previously mentioned studies longitudinal studies took into consideration the PA trajectories [22], understood as the longitudinal evolution of the PA participation. In this paper, moderate to vigorous PA trajectories were examined and related with changes in BMC, BMD, and strength at various sites. It was found that a high participation in moderate to vigorous PA during childhood led to bone strength benefits in late puberty. A more detailed analysis of VPA evolution could help understanding the relationship between PA activity and bone growth, since VPA is the activity intensity that is associated with higher changes in bone parameters [23, 24].

The main objective of this investigation was, thus, to analyze the effects of different longitudinal PA participation patterns on bone growth in healthy, early pubertal boys. More specifically, the link between bone development and both present and previous participation in VPA will be analyzed. This could help determining if bone response to VPA is dependent on previous activity history.

\section{Methods}

\section{Participants and study design}

From the initial sample of 264 healthy boys between 11 and 13 years of age at baseline from different schools in Tartu (Estonia) that took part in this longitudinal study, 140 completed all measurements at both time points and were included in this study (Fig. A1). Participants were required to have no restriction from participating in PA by their physicians. The initial tests included anthropometry and bone mineral measurements, skeletal maturation evaluation, and physical activity registration. These tests were repeated 1 year after the original measurements. The study protocol followed the ethical guidelines of the Declaration of Helisinki (revised in Fortaleza 2013) and was approved by the Human Ethical Committee of the University of Tartu, Estonia (179/T-4). Signed informed consent was retrieved from all the participants and their parents prior to the beginning of the tests. They were also given a full written description of the study characteristics before signing the informed consent.

\section{Anthropometry and bone mineral assessment}

Participants entered the anthropometric and bone mineral evaluation wearing light clothing and no shoes. Height was 
measured to the nearest $0.1 \mathrm{~cm}$ and body mass to the nearest $0.05 \mathrm{~kg}$ using Martin's metal anthropometer and a medical scale (A\&D Instruments Ltd.; Abingdon; UK) respectively.

Dual-energy X-ray absorptiometry (DPX-IQ densitometer, Lunar Corporation, Madison, WI, USA) was used to assess BMC (g) and BMD $\left(\mathrm{g} / \mathrm{cm}^{2}\right)$ at the whole body (WB), lumbar spine (L2 to L4, LS), and femoral neck (FN). The measurements were performed in the medium scan mode, with standard positioning. All scans and result evaluations at both baseline and follow-up were carried out by the same examiner, using the extended analysis option from the proprietary software (enCORE, version 3.6). Coefficients of variation for bone mineral measurements were below $2 \%$. Bone mineral apparent density (BMAD) was calculated following the formulas provided by Katzman et al. [25] and Carter el al. [26].

In order to assess the maturation status, participants had their skeletal age assessed by X-ray scans at the left hand and wrist, according to the method set by Greulich and Pyle $[27,28]$.

\section{Physical activity evaluation}

PA participation was assessed by means of a uniaxial accelerometer (GT1M Actigraph, Monrovia, CA, USA) that the participants wore on their right hip during 1 week. After aggregating data into 15 -s epoch periods, all intervals of zero counts lasting $20 \mathrm{~min}$ or more were removed from the analysis. All registers with less than 3 days without at least $10 \mathrm{~h}$ of valid data were excluded from posterior analyses. The intensity of the physical activity was established according to the Evenson cutpoints (sedentary activity $\leq 100 \mathrm{cpm}$, light activity $>100 \mathrm{cpm}$, moderate activity $\geq 2296 \mathrm{cpm}$, vigorous activity $\geq 4012 \mathrm{cpm}$ ) [29, $30]$. In order to analyze the distribution of VPA, the presence of VPA bouts was evaluated for each participant. To analyze the distribution of VPA over time, the consecutive periods (bouts) of VPA were analyzed. In order to be included in the analysis, the minimum duration of a bout was set at five consecutive minutes of VPA [31]. In order to assess the evolution of the PA participation over time, both the mean time and the difference of time spent in each activity intensity between both years was calculated.

Participants were divided according to their participation in VPA at baseline. Since the analysis of VPA distribution did not expose a clear cut-off point, the median value of the 140 participants (15.5 min per day) was used in order to obtain two groups with the same sample size. Then, the participation in VPA during the follow-up measurement (median $17.75 \mathrm{~min}$ per day) was used to further divide the original groups, thus obtaining four categories ("low-low," "low-high," "highlow," and "high-high") by taking into account the involvement in VPA at both time points.

\section{Statistical analysis}

Cluster analyses were used to generate bone growth profiles based on the variation of BMC and BMD (adjusted for change in body mass and bone age). Hierarchical and nonhierarchical clustering methods were combined in a two-step analysis [32]. A hierarchical cluster analysis, using Ward's method based on squared Euclidian distances, was used as a preliminary step to identify the cluster solutions. These extracted cluster centers served as nonrandom starting points in an iterative, nonhierarchical k-means clustering procedure that formed the definitive clusters.

Normality assumption was confirmed with KolmogorovSmirnov tests and the outlier presence was explored for all variables. Partial Pearson's correlation coefficients among change in bone mineral parameters and PA variables were calculated after adjustment by change in body mass and skeletal age. Analysis of covariance was used for the intergroup comparisons (VPA evolution and bone growth clusters), as well as repeated measures ANCOVA to test the group by time interaction. Changes in body weight and skeletal age were used as covariates for this analysis. Cross tabulation of the VPA and bone growth groups was performed and the chisquare statistic was calculated to assess the homogeneity of the group distributions. All statistical analyses were carried out with SPSS v22.0 for Windows (Chicago, IL, USA). Statistical significance was set at $p<0.05$.

\section{Results}

Results are shown only for those subjects who attended both bone mineral evaluations and provided enough valid data at both the baseline and the follow-up measurements (Fig. A1), which comprised a total of 140 participants. A full description of the sample characteristics at baseline can be found in Table 1.

The relationship between PA evolution with BMC and BMD change, after adjustment for changes in body mass and skeletal age, is presented in Table A1. Both the mean and the variation of the time spent practicing VPA intensities showed a small positive correlation with the change in BMD at the WB (mean 0.214; variation 0.198 , both $p<0.05$, Table 1) and the FN BMD (mean 0.245; variation 0.254, both $p<0.05$, Table 1 ). When looking at the mean of the overall PA participation, we can only find significant correlations with the FN BMD $(0.168, p<0.05$, Table A1). It should be mentioned that even though these results are statistically significant, the correlation coefficients are very small, with the highest $R^{2}$ being $6.5 \%$ (VPA difference-FN BMD).

Figure 1 and Table 2 show the baseline and follow-up values of BMC and BMD (after adjustment for body mass and skeletal age) at all sites measured, whereas Table 3 
Table 1 Baseline characteristics of the sample

$$
\text { All participants }(n=140) \quad \text { Low-low }(n=48) \quad \text { High-low }(n=22) \quad \text { Low-high }(\mathrm{n}=22) \quad \text { High-high }(\mathrm{n}=48)
$$

Age and body composition

\begin{tabular}{lccccc} 
Skeletal age (years) & $11.85 \pm 1.07$ & $11.92 \pm 0.73$ & $12.00 \pm 0.61$ & $12.33 \pm 0.72$ & $12.04 \pm 0.65$ \\
Height (cm) & $154.3 \pm 7.5$ & $153.1 \pm 7.3$ & $155.2 \pm 6.0$ & $155.9 \pm 9.1$ & $154.5 \pm 7.6$ \\
Body weight (kg) & $47.0 \pm 12.5$ & $49.4 \pm 14.6$ & $46.4 \pm 11.8$ & $49.7 \pm 13.6$ & $43.6 \pm 9.2$ \\
Fat mass (kg) & $11.4 \pm 8.4$ & $14.4 \pm 9.7$ & $9.8 \pm 6.7$ & $12.5 \pm 9.2$ & $8.5 \pm 5.9^{*}$ \\
Lean mass (kg) & $33.0 \pm 5.7$ & $32.3 \pm 5.8$ & $34.0 \pm 5.3$ & $34.5 \pm 7.4$ & $32.7 \pm 4.8$ \\
Physical activity & & & & $517.1 \pm 57.0^{*}$ \\
Sedentary time (min/day) & $545.2 \pm 75.6$ & $574.8 \pm 89.3$ & $528.1 \pm 47.5$ & $559.1 \pm 78.4$ & $241.5 \pm 47.0$ \\
Light PA (min/day) & $234.4 \pm 47.0$ & $228.3 \pm 51.7$ & $241.9 \pm 43.3$ & $224.9 \pm 38.8$ & $46.5 \pm 15.5^{*}-$ \\
Moderate PA (min/day) & $39.4 \pm 14.5$ & $32.1 \pm 10.8$ & $44.0 \pm 13.5^{*}$ & $35.0 \pm 11.2$ & $30.7 \pm 13.2^{*}-$ \\
Vigorous PA (min/day) & $18.7 \pm 13.2$ & $8.3 \pm 3.7$ & $23.2 \pm 7.4^{*}$ & $10.9 \pm 3.8^{\dagger}$ & $591.3 \pm 139.7^{*}$ \\
Overall PA (counts/min) & $476.2 \pm 151.3$ & $367.7 \pm 89.5$ & $534.0 \pm 125.2^{*}$ & $401.7 \pm 86.5^{\dagger}$ & \\
\hline
\end{tabular}

VPA cutpoint at baseline, $15.5 \mathrm{~min} /$ day; VPA cutpoint at follow-up, $17.75 \mathrm{~min} /$ day

*Significant differences compared to low-low group $(p<0.05)$

${ }^{\dagger}$ Significant differences compared to high-low group $(p<0.05)$

${ }^{\lrcorner}$Significant differences compared to low-high group $(p<0.05)$

Values are expressed as mean \pm standard deviation

presents the change in these variables over time. All the groups showed statistically significant increases over time for BMC and BMD at all regions measured. All the differences found at baseline (WB, FN and LS BMC and FN BMD) disappear at follow-up for the "low-high" group. Moreover, significant differences with the "low-low" were found at follow-up for femoral neck BMC (low-low 4.203, low-high $4.530 \mathrm{~g} ; p<0.05$ ) and BMD (low-low 0.898, low-high $0.958 \mathrm{~g} / \mathrm{cm}^{2} ; p<0.05$ ). Additionally, when comparing BMC and BMD changes, it was observed that the "low-high" group shows higher increases for all bone mineral variables except WB BMC than the "low-low" group and also greater growth than the "high-low" group for WB BMD and FN BMC and BMD (Table 3 , all $p<0.05$ ). For the change in BMAD, the only significant differences were found at the whole body (low-low -2.73 , high-low -3.46 , low-high -0.55 , $p>0.05$ ).

The cluster analysis and the posterior categorization created three clearly defined groups according to bone growth, as illustrated in Table 4. When comparing the PA participation of the different bone growth groups, it could be observed that the only differences between the optimal and the reduced growth groups were found in the VPA and its maximum bout duration (Table 4). Regarding the relative distribution of the bone growth and VPA groups, shown in Fig. 2, a trend for a heterogeneous distribution of the groups was found $\left(\chi^{2} 10.76, p=0.096\right)$. If the "mean growth" group is excluded from the analysis, statistical significance is reached $\left(\chi^{2} 9.26, p=0.026\right)$, with the "low-high" group showing the highest percentage of subjects with optimal growth $(36.3 \%)$ and the "low-low"
$(12.5 \%)$ and "high-low" (13.6\%) showing the lowest proportion of "optimal growth" participants.

\section{Discussion}

The main finding of the present study was that engaging in VPA during puberty stimulates bone growth especially in subjects who were in the low-VPA group at baseline. This implies that adolescents engaging in VPA during early puberty are still able to reach BMD values that are similar in comparison with previously active children. The high responsiveness of the bone tissue to VPA during puberty was indicated in most sites by higher bone growth in subjects who increased their participation in VPA compared to those subjects who were vigorously active at baseline but were below the median at followup.

The analysis of the correlations between mean PA and bone mineral acquisition complements previously published data [33]. The previous analyses focused solely in the changes in PA participation and consequently did not discriminate those subjects who remained physically active throughout the study from those who showed low levels of PA participation during the same period. The longitudinal associations among overall and VPA with BMC and BMD are in accordance with previous studies [34]. It is important to notice that not only the mean participation in VPA was related to bone growth but its variation as well, indicating that both engaging into and maintaining high levels of VPA participation can positively affect bone accretion. This is further supported by the results obtained in the cluster comparison, with the "optimal growth" 
WB BMC (g)

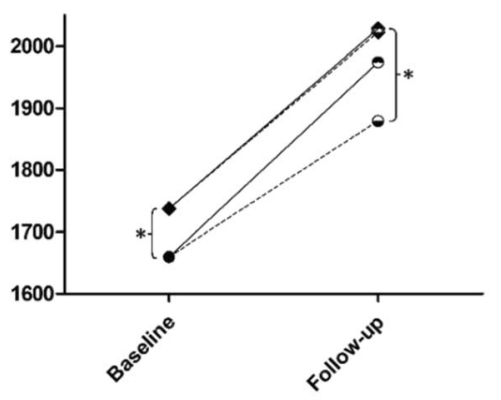

FN BMC (g)

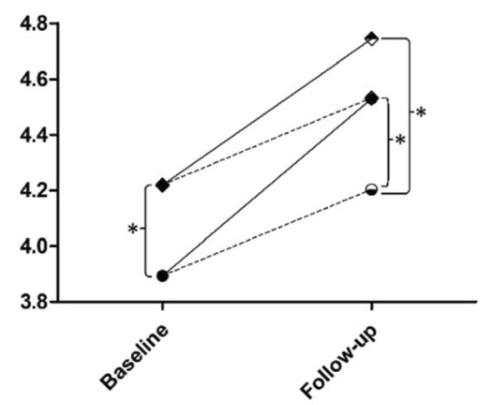

LS BMC (g)

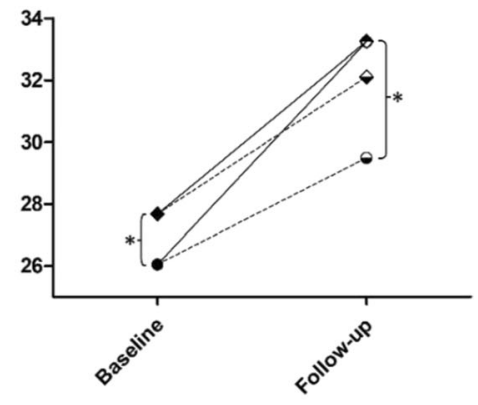

- $\operatorname{Low}$-Low $(n=48) \rightarrow \operatorname{High}-\operatorname{Low}(n=22) \quad \operatorname{Low}-\operatorname{High}(n=22) \rightarrow \operatorname{High}-\operatorname{High}(n=48)$

WB BMD $\left(\mathrm{g} / \mathrm{cm}^{2}\right)$

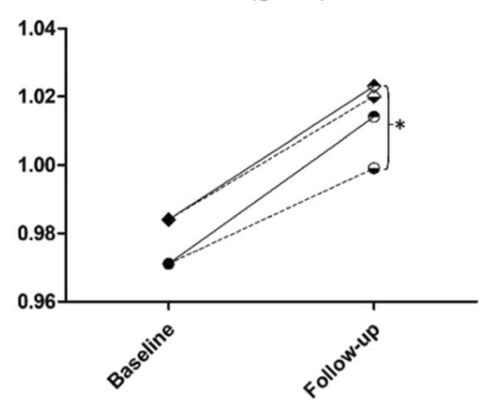

FN BMD $\left(\mathrm{g} / \mathrm{cm}^{2}\right)$

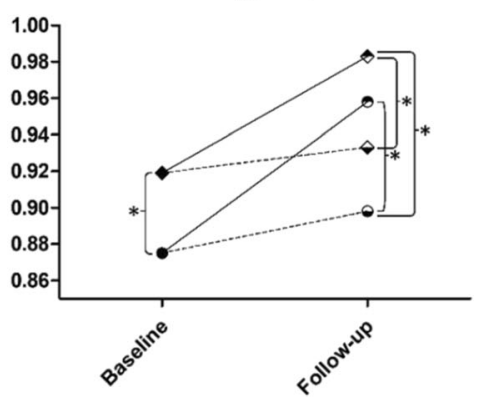

LS BMD $\left(\mathrm{g} / \mathrm{cm}^{2}\right)$

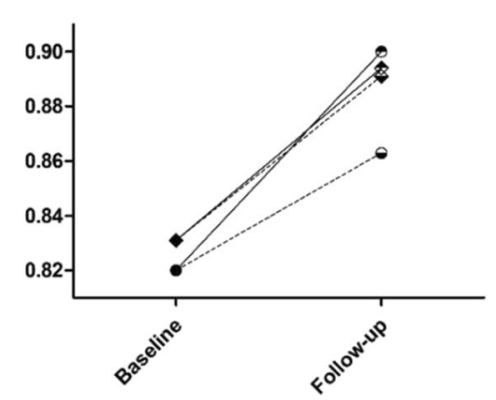

Fig. 1 Baseline and follow-up bone mineral parameters according to vigorous physical activity groups. VPA cutpoint at baseline, $15.5 \mathrm{~min} / \mathrm{day}$; VPA cutpoint at follow-up, $17.75 \mathrm{~min} /$ day. *Significant differences between groups $(p<0.05)$

group having the highest levels of VPA participation. The rest of the activity intensities did not correlate with bone growth, which is in accordance with previous studies, especially in boys [35-37]. However, as it has been mentioned, it should be taken into account that the correlation coefficients found are very small and the highest variance explained was only

Table 2 Bone mineral parameters (after adjustment for skeletal age and body weight) according to different vigorous activity evolution patterns

\begin{tabular}{|c|c|c|c|c|c|c|}
\hline \multirow[b]{2}{*}{ Bone mineral parameters } & \multicolumn{2}{|l|}{ Baseline } & \multicolumn{4}{|l|}{ Follow-up } \\
\hline & Low $(n=70)$ & $\operatorname{High}(n=70)$ & Low-low $(n=48)$ & High-low $(n=22)$ & Low-high $(n=22)$ & High-high $(n=48)$ \\
\hline WB BMC (g) & $1660 \pm 20$ & $1738 \pm 20$ & $1879 \pm 32$ & $2023 \pm 46^{*}$ & $1974 \pm 47$ & $2028 \pm 32 *$ \\
\hline WB BMD $\left(\mathrm{g} / \mathrm{cm}^{2}\right)$ & $0.971 \pm 0.006$ & $0.984 \pm 0.006$ & $0.999 \pm 0.008$ & $1.014 \pm 0.012$ & $1.020 \pm 0.012$ & $1.023 \pm 0.008^{*}$ \\
\hline WB BMAD (g/cm³ $)$ & $0.089 \pm 0.001$ & $0.088 \pm 0.001$ & $0.086 \pm 0.001$ & $0.085 \pm 0.001$ & $0.087 \pm 0.001$ & $0.086 \pm 0.001$ \\
\hline FN BMC (g) & $3.89 \pm 0.06$ & $4.22 \pm 0.06$ & $4.203 \pm 0.081$ & $4.533 \pm 0.118^{*}$ & $4.530 \pm 0.119^{*}$ & $4.745 \pm 0.081 *$ \\
\hline FN BMD $\left(\mathrm{g} / \mathrm{cm}^{2}\right)$ & $0.875 \pm 0.010$ & $0.919 \pm 0.010$ & $0.898 \pm 0.013$ & $0.933 \pm 0.019$ & $0.958 \pm 0.019^{*}$ & $0.983 \pm 0.013 *^{\dagger}$ \\
\hline FN BMAD $\left(\mathrm{g} / \mathrm{cm}^{3}\right)$ & $0.197 \pm 0.003$ & $0.202 \pm 0.003$ & $0.194 \pm 0.003$ & $0.196 \pm 0.005$ & $0.204 \pm 0.005$ & $0.206 \pm 0.003^{*}$ \\
\hline LS BMC (g) & $26.05 \pm 0.55$ & $27.67 \pm 0.55$ & $29.49 \pm 0.82$ & $32.12 \pm 1.20$ & $33.25 \pm 1.20 *$ & $33.25 \pm 0.82 *$ \\
\hline LS BMD $\left(\mathrm{g} / \mathrm{cm}^{2}\right)$ & $0.820 \pm 0.009$ & $0.831 \pm 0.009$ & $0.863 \pm 0.013$ & $0.891 \pm 0.019$ & $0.900 \pm 0.019$ & $0.894 \pm 0.094$ \\
\hline LS BMAD $\left(\mathrm{g} / \mathrm{cm}^{3}\right)$ & $0.147 \pm 0.002$ & $0.144 \pm 0.002$ & $0.149 \pm 0.002$ & $0.150 \pm 0.003$ & $0.149 \pm 0.003$ & $0.148 \pm 0.002$ \\
\hline
\end{tabular}

VPA cutpoint at baseline, $15.5 \mathrm{~min} /$ day; VPA cutpoint at follow-up, $17.75 \mathrm{~min} /$ day

Bold characters indicate significant differences between groups at baseline

* Significant differences compared to low-low group $(p<0.05)$

${ }^{\dagger}$ Significant differences compared to high-low group $(p<0.05)$

$W B$ whole body, $F N$ femoral neck, $L S$ lumbar spine, $B M C$ bone mineral content, $B M D$ bone mineral density, $B M A D$ bone mineral apparent density

Values are expressed as mean \pm standard error 
6.5\%, between VPA difference and FN BMD. It should be taken into account that the current 1-year study period might have been too short for detecting the influence of lower intensity activities to bone mineral parameters. The results found are in accordance with the mechanostat theorem [38], which states that the mechanical load exerted on bone during PA can stimulate bone remodeling, affecting bone mineral content and structure.

The FN is the skeletal site that showed the highest association with PA parameters, which could be due to the highest responsiveness of cortical bone to physical stimulus $[39,40]$. Despite being unable to test this in our sample, given that the method used does not allow for cortical and trabecular bone discrimination, the responsiveness of $\mathrm{FN}$ bone to continued PA is relevant, since a high proportion of osteoporotical fractures occur in this region [1].

The evolution of the overall PA and the moderate to vigorous PA trajectories have already been related to bone mass and structure [22]. The division of the sample into different PA patterns was done following the method used by Janz et al. [22] with the difference that it was applied using VPA instead of overall activity. At baseline, those subjects who were above and below the median value of VPA differed in their BMC at all sites and the FN BMD. At follow-up, however, all these differences disappeared for the subjects who started participating in VPA ("low-high" group). This finding further indicates the importance of intense PA for bone accrual and the resulting peak bone mass. Incorporating vigorous PA to daily routine might help optimizing bone accrual to previously inactive subjects. Particularly, at the FN, statistically significant differences emerged from the "low-high" group and the "low-low" group. The "low-high" group showed greater growth in bone mass and density than both groups who were below the median VPA at follow-up. In contrast, subjects who stopped practicing VPA ("high-low" group) reported lower BMD values at the FN compared to the "high-high" group. Nonetheless, the differences with the "low-low" group remained significant for the WB and FN BMC. This benefits, however seem to be limited to areal BMD, greater increases of BMAD were only found for the "low-high" group at the whole body. This may be caused by an increase in bone size along the increase in areal BMD.

When analyzing growth profiles, three clearly defined groups emerged. The main difference between the "optimal" and the "reduced" growth groups was observed in the VPA and its maximum bout duration. As it has been shown, the "low-high" group had the greatest percentage of participants who experienced an improved gain of BMC and BMD at all measured sites.

These results point to an enhancing effect of VPA on bone development during puberty. As it has been shown, bone formation is stimulated by the physical stress produced by VPA practice [41] and early puberty is a stage in which bone is 
Table 4 Physical activity participation (mean of baseline and follow-up) and bone mineral parameters (difference of followup and baseline) according to different bone development patterns

\begin{tabular}{|c|c|c|c|}
\hline & $\begin{array}{l}\text { Optimal growth } \\
(n=29)\end{array}$ & $\begin{array}{l}\text { Mean growth } \\
(n=58)\end{array}$ & $\begin{array}{l}\text { Reduced growth } \\
(n=53)\end{array}$ \\
\hline \multicolumn{4}{|l|}{ Physical activity } \\
\hline Sedentary time (min/day) & $568.0 \pm 61.8$ & $547.8 \pm 69.4$ & $563.4 \pm 68.1$ \\
\hline Light PA (min/day) & $210.6 \pm 38.8$ & $227.1 \pm 38.1$ & $218.1 \pm 39.7$ \\
\hline Moderate PA (min/day) & $36.1 \pm 12.9$ & $37.8 \pm 12.2$ & $37.8 \pm 13.0$ \\
\hline Vigorous PA (min/day) & $23.2 \pm 14.5$ & $21.3 \pm 14.2$ & $17.1 \pm 9.1 *$ \\
\hline Overall PA (counts/min) & $468.7 \pm 159.1$ & $483.3 \pm 151.4$ & $445.2 \pm 111.6$ \\
\hline $\begin{array}{l}\text { Time in vigorous PA bouts } \\
(\mathrm{min} / \text { day })\end{array}$ & $4.72 \pm 4.64$ & $3.70 \pm 4.49$ & $2.88 \pm 5.32$ \\
\hline Maximum bout duration (min) & $10.38 \pm 6.18$ & $8.09 \pm 4.59$ & $6.98 \pm 5.49^{*}$ \\
\hline \multicolumn{4}{|c|}{ Difference in bone mineral parameters ${ }^{\mathrm{a}}$} \\
\hline WB BMC (g) & $441 \pm 78$ & $260 \pm 75^{*}$ & $184 \pm 61 * \dagger$ \\
\hline WB BMD $\left(\mathrm{g} / \mathrm{cm}^{2}\right)$ & $0.065 \pm 0.010$ & $0.037 \pm 0.009^{*}$ & $0.017 \pm 0.008 * \dagger$ \\
\hline FN BMC (g) & $0.897 \pm 0.153$ & $0.429 \pm 0.160^{*}$ & $0.189 \pm 0.125^{* \dagger}$ \\
\hline FN BMD $\left(\mathrm{g} / \mathrm{cm}^{2}\right)$ & $0.106 \pm 0.016$ & $0.048 \pm 0.017 *$ & $0.008 \pm 0.013 * \dagger$ \\
\hline LS BMC (g) & $9.82 \pm 1.39$ & $4.75 \pm 1.52^{*}$ & $2.43 \pm 1.20 * \dagger$ \\
\hline $\operatorname{LS}$ BMD $\left(\mathrm{g} / \mathrm{cm}^{2}\right)$ & $0.124 \pm 0.015$ & $0.060 \pm 0.016^{*}$ & $0.020 \pm 0.013 * \dagger$ \\
\hline \multicolumn{4}{|c|}{ Values are expressed as mean \pm standard deviation } \\
\hline \multicolumn{4}{|c|}{${ }^{\mathrm{a}}$ Adjusted for difference in skeletal age and body weight } \\
\hline \multicolumn{4}{|c|}{ *Significant differences compared to optimal growth group $(\mathrm{p}<0.05)$} \\
\hline \multicolumn{4}{|c|}{${ }^{\dagger}$ Significant differences compared to mean growth group $(p<0.05)$} \\
\hline
\end{tabular}

particularly responsive to this stimulus [14, 42]. It seems that osteocytes play a crucial role in the physiological response of bone, stimulating osteoblastic activity in the presence of mechanical loads while increasing bone resorption in the absence of mechanical strain [43]. According to our results, participation in unstructured VPA seems to provide a mechanical load that is sufficient to elicit an osteogenic response following the mechanostat theorem [38].

This increase in BMC and BMD has been observed in our sample with participants who engaged in VPA during the follow-up independently of their previous activity. However,

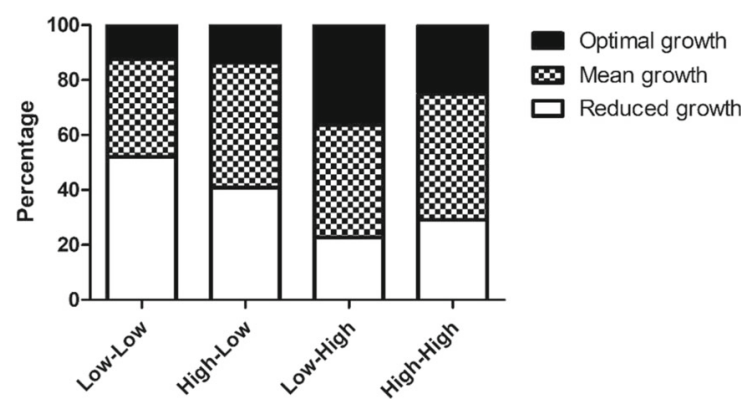

VPA cutpoint at baseline: $15.5 \mathrm{~min} /$ day; VPA cutpoint at follow up: $17.75 \mathrm{~min} /$ day

Fig. 2 Relative distribution of growth profiles across vigorous physical activity groups. VPA cutpoint at baseline, $15.5 \mathrm{~min} /$ day; VPA cutpoint at follow-up, $17.75 \mathrm{~min} /$ day it should be pointed out that initial VPA led to a higher bone mineral status and these benefits were maintained after activity cessation, as it has been suggested by previous research $[14,19]$.

The 1-year follow-up design as well as the approach used in the analysis of the evolution of PA participation are among the main strengths of this study, alongside with the employment of objective measures for the PA evaluation and gold standard reference methods for the bone mineral assessment. The lack of a PA intervention and a control group with no exercise does not allow to infer causal relationships and is one of the main limitations that should be taken into account. Also, bone structure was not evaluated due to the bidimensional nature of the bone assessment method. It should also be acknowledged that no nutritional status evaluation was performed and therefore, the possible effects of diet on bone parameters were not controlled in the present study. The analysis of longitudinal changes in bone structure or specific adaptations in cortical or trabecular bone related to PA could be the scope for future research.

As a conclusion, both engaging and maintaining high levels of VPA participation during puberty are associated with greater gains in bone mass and density, especially at the femoral neck, where the increase in BMD for the "low-high" group almost doubled the increase found in both "high-low" and "low-low" groups. An interesting conclusion that can be 
drawn from our results is that engaging in VPA during early puberty can result in increased bone growth, regardless of previous activity levels. Additionally, these benefits could be preserved even after activity cessation.

Funding JMP received a grant from 'Ministerio de Educación Cultura y Deportes' (FPU014/04302). This study was funded by the Estonian Ministry of Education and Science (IUT 20-58).

\section{Compliance with ethical standards}

The study protocol followed the ethical guidelines of the Declaration of Helisinki and was approved by the Human Ethical Committee of the University of Tartu, Estonia (179/T-4). Signed informed consent was retrieved from all the participants and their parents prior to the beginning of the tests. They were also given a full written description of the study characteristics before signing the informed consent.

\section{Conflicts of interest None}

\section{References}

1. Hernlund E, Svedbom A, Ivergård $\mathrm{M}$, Compston J, Cooper C, Stenmark J, McCloskey EV, Jönsson B, Kanis JA (2013) Osteoporosis in the European Union: medical management, epidemiology and economic burden: a report prepared in collaboration with the International Osteoporosis Foundation (IOF) and the European Federation of Pharmaceutical Industry Associations (EFPIA). Arch Osteoporos 8(136):136. https://doi.org/10.1007/ s11657-013-0136-1

2. Wright NC, Looker AC, Saag KG, Curtis JR, Delzell ES, Randall S, Dawson-Hughes B (2014) The recent prevalence of osteoporosis and low bone mass in the United States based on bone mineral density at the femoral neck or lumbar spine. J Bone Miner Res 29:2520-2526. https://doi.org/10.1002/jbmr.2269

3. Peck WA, Burckhardt P, Christiansen C et al (1993) Consensus development conference: diagnosis, prophylaxis, and treatment of osteoporosis. American Journal of Medicine, In, pp 646-650

4. Bliuc D, Nguyen ND, Milch VE, Nguyen TV, Eisman JA, Center JR (2009) Mortality risk associated with low-trauma osteoporotic fracture and subsequent fracture in men and women. JAMA 301: 513-521. https://doi.org/10.1001/jama.2009.50

5. Cooper C, Cole ZA, Holroyd CR et al (2011) Secular trends in the incidence of hip and other osteoporotic fractures. Osteoporos Int 22: $1277-1288$

6. Rizzoli R, Bianchi ML, Garabédian M, McKay HA, Moreno LA (2010) Maximizing bone mineral mass gain during growth for the prevention of fractures in the adolescents and the elderly. Bone 46: 294-305. https://doi.org/10.1016/j.bone.2009.10.005

7. Pocock NA, Eisman JA, Hopper JL, Yeates MG, Sambrook PN, Eberl S (1987) Genetic determinants of bone mass in adults: a twin study. J Clin Invest 80:706-710. https://doi.org/10.1172/jci113125

8. Vicente-Rodríguez G (2006) How does exercise affect bone development during growth? Sport Med 36:561-569

9. Baxter-Jones ADG, Faulkner RA, Forwood MR, Mirwald RL, Bailey DA (2011) Bone mineral accrual from 8 to 30 years of age: an estimation of peak bone mass. J Bone Miner Res 26: 1729-1739. https://doi.org/10.1002/jbmr.412

10. Bonjour JP, Chevalley T, Ferrari S, Rizzoli R (2009) The importance and relevance of peak bone mass in the prevalence of osteoporosis. Salud Publica Mex 51:5-17. https://doi.org/10.1590/ S0036-36342009000700004

11. Weaver CM, Gordon CM, Janz KF, Kalkwarf HJ, Lappe JM, Lewis R, O'Karma M, Wallace TC, Zemel BS (2016) The National Osteoporosis Foundation's position statement on peak bone mass development and lifestyle factors: a systematic review and implementation recommendations. Osteoporos Int 27:1281-1386. https:// doi.org/10.1007/s00198-015-3440-3

12. Poitras VJ, Gray CE, Borghese MM, Carson V, Chaput JP, Janssen I, Katzmarzyk PT, Pate RR, Connor Gorber S, Kho ME, Sampson M, Tremblay MS (2016) Systematic review of the relationships between objectively measured physical activity and health indicators in school-aged children and youth. Appl Physiol Nutr Metab 6: S197-S239. https://doi.org/10.1139/apnm-2015-0663

13. Lappe JM, Watson P, Gilsanz V, Hangartner T, Kalkwarf HJ, Oberfield S, Shepherd J, Winer KK, Zemel B (2015) The longitudinal effects of physical activity and dietary calcium on bone mass accrual across stages of pubertal development. J Bone Miner Res 30:156-164. https://doi.org/10.1002/jbmr.2319

14. Gunter KB, Almstedt HC, Janz KF (2012) Physical activity in childhood may be the key to optimizing lifespan skeletal health. Exerc Sport Sci Rev 40:13-21. https://doi.org/10.1097/JES. 0b013e318236e5ee.Physical

15. Robling AG (2009) Is bone's response to mechanical signals dominated by muscle forces? Med Sci Sports Exerc 41:2044-2049. https://doi.org/10.1249/MSS.0b013e3181a8c702

16. Borer KT (2005) Physical activity in the prevention and amelioration of osteoporosis in women: interaction of mechanical, hormonal and dietary factors. Sports Med 35:779-830

17. Holroyd C, Harvey N, Dennison E, Cooper C (2012) Epigenetic influences in the developmental origins of osteoporosis. Osteoporos Int 23:401-410. https://doi.org/10.1007/s00198-011-1671-5

18. Daly RM (2007) The effect of exercise on bone mass and structural geometry during growth. Med Sport Sci 51:33-49. https://doi.org/ $10.1159 / 0000103003$

19. Gunter K, Baxter-Jones AD, Mirwald RL et al (2007) Impact exercise increases BMC during growth: an 8-year longitudinal study. J Bone Miner Res 23:986-993. https://doi.org/10.1359/jbmr.071201

20. Janz KF, Letuchy EM, Francis SL, Metcalf KM, Burns TL, Levy SM (2014) Objectively measured physical activity predicts hip and spine bone mineral content in children and adolescents ages 5-15 years: Iowa bone development study. Front Endocrinol (Lausanne) 5:1-7. https://doi.org/10.3389/fendo.2014.00112

21. Gracia-Marco L, Moreno LA, Ortega FB, León F, Sioen I, Kafatos A, Martinez-Gomez D, Widhalm K, Castillo MJ, VicenteRodríguez G, HELENA Study Group (2011) Levels of physical activity that predict optimal bone mass in adolescents: The HELENA study. Am J Prev Med 40:599-607. https://doi.org/10. 1016/j.amepre.2011.03.001

22. Janz KF, Letuchy EM, Burns TL et al (2014) Objectively measured physical activity trajectories predict adolescent bone strength: Iowa Bone Development Study. Br J Sports Med 48:1032-1036. https:// doi.org/10.1249/MSS.0000000000000648

23. Cardadeiro G, Baptista F, Ornelas R, Janz KF, Sardinha LB (2012) Sex specific association of physical activity on proximal femur BMD in 9 to 10 year-old children. PLoS One 7:e50657. https:// doi.org/10.1371/journal.pone.0050657

24. Hasselstrøm H, Karlsson KM, Hansen SE, Grønfeldt V, Froberg K, Andersen LB (2007) Peripheral bone mineral density and different intensities of physical activity in children 6-8 years old: the Copenhagen School Child Intervention Study. Calcif Tissue Int 80:31-38. https://doi.org/10.1007/s00223-006-0137-9

25. Katzman DK, Bachrach LK, Carter DR, Marcus R (1991) Clinical and anthropometric correlates of bone mineral acquisition in healthy adolescent girls*. J Clin Endocrinol Metab 73:13321339. https://doi.org/10.1210/jcem-73-6-1332 
26. Carter DR, Bouxsein ML, Marcus R (2009) New approaches for interpreting projected bone densitometry data. J Bone Miner Res 7: 137-145. https://doi.org/10.1002/jbmr.5650070204

27. Greulich WW, Pyle SI (1959) Radiographic atlas of skeletal development of the hand and wrist. Am J Med Sci 238:393

28. Groell R, Lindbichler F, Riepl T, Gherra L, Roposch A, Fotter R (1999) The reliability of bone age determination in central European children using the Greulich and Pyle method. Br J Radiol 72:461-464. https://doi.org/10.1259/bjr.72.857.10505010

29. Evenson KR, Catellier DJ, Gill K, Ondrak KS, McMurray RG (2008) Calibration of two objective measures of physical activity for children. J Sports Sci 26:1557-1565

30. Trost SG, Loprinzi PD, Moore R, Pfeiffer KA (2011) Comparison of accelerometer cut points for predicting activity intensity in youth. Med Sci Sports Exerc 43:1360-1368. https://doi.org/10.1249/MSS. 0b013e318206476e

31. Holman RM, Carson V, Janssen I (2011) Does the fractionalization of daily physical activity (sporadic vs. bouts) impact cardiometabolic risk factors in children and youth? PLoS One 6:1-7. https:// doi.org/10.1371/journal.pone.0025733

32. Gore PA (2000) Cluster analysis. In: Tinsley HEA, Brown SD (eds) Handbook of Applied Multivariate Statistics and Mathematical Modeling. Academic Press, San Diego, pp 297-321

33. Ivuškāns A, Mäestu J, Jürimäe T, Lätt E, Purge P, Saar M, Maasalu K, Jürimäe J (2015) Sedentary time has a negative influence on bone mineral parameters in peripubertal boys: a 1-year prospective study. J Bone Miner Metab 33:85-92. https://doi.org/10.1007/ s00774-013-0556-4

34. Francis SL, Letuchy EM, Levy SM, Janz KF (2014) Sustained effects of physical activity on bone health: Iowa Bone Development Study. Bone 63:95-100. https://doi.org/10.1016/j. bone.2014.03.004

35. Christoffersen T, Winther A, Nilsen OA, Ahmed LA, Furberg AS, Grimnes G, Dennison E, Emaus N (2015) Does the frequency and intensity of physical activity in adolescence have an impact on bone? The Tromsø Study, Fit Futures. BMC Sports Sci Med Rehabil 7:26. https://doi.org/10.1186/s13102-015-0020-y

36. Sayers A, Mattocks C, Deere K, Ness A, Riddoch C, Tobias JH (2011) Habitual levels of vigorous, but not moderate or light, physical activity is positively related to cortical bone mass in adolescents. J Clin Endocrinol Metab 96:793-802. https://doi.org/10. 1210/jc.2010-2550

37. Deere K, Sayers A, Rittweger J, Tobias JH (2012) Habitual levels of high, but not moderate or low, impact activity are positively related to hip BMD and geometry: results from a population-based study of adolescents. J Bone Miner Res 27:1887-1895. https://doi.org/10. $1002 / j b m r .1631$

38. Frost HM (2003) Bone's mechanostat: a 2003 update. Anat Rec Part A Discov Mol Cell Evol Biol 275:1081-1101

39. Bakker I, Twisk JWR, Van Mechelen W, Kemper HCG (2003) Fatfree body mass is the most important body composition determinant of 10-yr longitudinal development of lumbar bone in adult men and women. J Clin Endocrinol Metab 88:2607-2613. https://doi.org/10. 1210/jc.2002-021538

40. Kriemler S, Zahner L, Puder JJ, Braun-Fahrländer C, Schindler C, Farpour-Lambert NJ, Kränzlin M, Rizzoli R (2008) Weight-bearing bones are more sensitive to physical exercise in boys than in girls during pre- and early puberty: a cross-sectional study. Osteoporos Int 19:1749-1758. https://doi.org/10.1007/s00198-008-0611-5

41. Marcus R (1996) Mechanisms of exercise effects on bone. Princ bone Biol 151:1135-1146

42. MacKelvie KJ, Khan KM, McKay HA (2002) Is there a critical period for bone response to weight-bearing exercise in children and adolescents? A systematic review. Br J Sports Med 36:250257. https://doi.org/10.1136/bjsm.36.4.250

43. Klein-Nulend J, Bacabac RG, Bakker AD (2012) Mechanical loading and how it affects bone cells: the role of the osteocyte cytoskeleton in maintaining our skeleton. Eur Cell Mater 24:278-291 